\title{
Parasitoid complex and parasitism rates of the horse chestnut leafminer, Cameraria ohridella (Lepidoptera: Gracillariidae) in the Czech Republic, Slovakia and Slovenia
}

\author{
LuBomír VOLTER ${ }^{1}$ and MARC KENIS ${ }^{2}$

\begin{abstract}
${ }^{1}$ Department of Biology, University of West Bohemia, Klatovská 51, CZ-30619 Plzeň, Czech Republic; e-mail: lvolter@post.cz ${ }^{2}$ CABI Bioscience Switzerland Centre, 1, Rue des Grillons, 2800 Delémont, Switzerland; e-mail: m.kenis@cabi.org
\end{abstract}

Key words. Cameraria ohridella, Gracillariidae, Eulophidae, parasitoids, parasitism rate, mortality rate, horse chestnut, Aesculus hippocastanum

\begin{abstract}
The horse chestnut leaf miner, Cameraria ohridella Deschka \& Dimić, is a species of unknown origin that recently invaded most of Europe, causing serious damage to horse chestnut trees, Aesculus hippocastanum. Parasitism was studied over a period of three years in the region of Plzeň in the Czech Republic. Additional collections were made in Slovakia and Slovenia. The parasitoid complex, dominated by polyphagous idiobiont parasitoids of the family Eulophidae, is similar to that found in other studies in Europe. Minotetrastichus frontalis (Nees) was the most abundant parasitoid found, except in Slovakia where Pediobius saulius (Walker) dominated. One parasitoid species, the eulophid Cirrospilus diallus (Walker) was recorded for the first time from C. ohridella. A new method is proposed to calculate stage-specific and total parasitism rates. Parasitism rates of spinning larvae and pupae were higher than of feeding larvae; however, total parasitism was low. We estimated that between $1 \%$ and $17 \%$ of moths died from parasitism during the larval and pupal stages whereas the rate of mortality caused by other factors varied from $7 \%$ to $62 \%$, depending on the locality, year and generation. The proposed method for calculating total parasitism, based on the integration of stage-specific parasitism rates, which takes into account the mortality not directly attributed to parasitism, is discussed and compared with other methods commonly used in studies on C. ohridella.
\end{abstract}

\section{INTRODUCTION}

In the last 30 years, several alien leaf mining moths, mainly of the family Gracillariidae, invaded Central Europe (Šefrová, 1998, 2002a, b, c). As is often the case with alien species, these leaf miners usually reach higher population densities than indigenous leaf miners. When invading a new region, leaf miners are adopted by a number of native, polyphagous natural enemies, in particular parasitoids. However, the impact of these native parasitoids on host populations strongly depends on host species (Godfray et al., 1995; Gibogini et al., 1996; Urbaneja et al., 2000). One of these invasive species is the horse chestnut leaf miner, Cameraria ohridella, Deschka \& Dimić (Lepidoptera: Gracillariidae), a moth of unknown origin that was first observed in Macedonia in 1984. It has since invaded most of Europe, causing important aesthetic damage to horse chestnut, Aesculus hippocastanum L., a widely planted urban tree throughout the continent (Freise \& Heitland, 2004). The moth was first noticed in the Czech Republic in 1994 (Laštůvka et al., 1994). Parasitism by indigenous, polyphagous parasitoids has been investigated in several countries and is believed to have a low impact on $C$. ohridella populations. Parasitism rates cited in the literature usually vary between 1-10\% (e.g. Freise et al., 2002; Marchesini et al., 2002; Grabenweger, 2003; Freise \& Heitland, 2004). However, parasitism rates and their meaning greatly vary with the method used (Van Driesche, 1983). Ideally, they should be adapted to each host-parasitoid complex system to match percent parasitism with the real impact of the parasitoids. When measuring parasitism in leaf mining moths, the following factors have to be taken into account: (1) Super-, multi- and hyperparasitism are common, and several parasitoids of the same or different species may emerge from a single host. Therefore, measuring parasitism purely by emergence data from leaves should be avoided. Instead, parasitism should be measured by dissection. (2) Mortality rates in collected material tend to vary between hosts and parasitoids as well as among parasitoid species, suggesting again that parasitism would be better determined by dissection. (3) Most parasitoids that attack an alien leaf mining moth, are polyphagous and idiobionts, i.e. host development ceases when parasitised. They tend to attack mainly the late developmental stages (spinning larvae and pupae) and thus collections made during the feeding stages will largely underestimate parasitism. On the other hand, collections made later in the life cycle may overestimate parasitism if emerged hosts are not included in the calculation. (4) Many hosts are killed by parasitoid hostfeeding, which should also be taken into account when measuring the impact of parasitoids. Previous studies on parasitism of $C$. ohridella have calculated parasitism rates based on emergence data (e.g. Grabenweger \& Lethmayer, 1999; Hellrigl, 2001; Grabenweger, 2003) or, when dissections of single mines were made, parasitism rates were obtained simply by dividing the number of parasitised mines by the total number of mines (e.g. Freise et al., 2002; Grabenweger et al., 2005; Lupi, 2005). 
These calculations may result in a bias in the estimates of parasitism rates, for the reasons mentioned above.

The main aims of this study were to collect data on the parasitoid complex of C. ohridella in the Czech Republic, Slovakia and Slovenia, and to estimate the rate of parasitism and of other mortality factors using a more appropriate method than that commonly utilised in previous studies.

\section{MATERIAL AND METHODS}

\section{Parasitoids of Cameraria ohridella}

Samples of horse chestnut leaves infested with $C$. ohridella were collected over a three year period at five locations in the Czech Republic, one location in Slovakia and one location in Slovenia. In 2001 the following locations were sampled: Bolevec, Košutka, Lochotín and Mikulka (all in Plzeň, Czech Republic). In 2002, leaves were sampled at these same four locations as well as in Otín (near Klatovy, $40 \mathrm{~km}$ south of Plzeň, Czech Republic). In 2003, collections were made again in Bolevec and Otín, and single samples were also taken in Ilava (125 km northeast of Bratislava, Slovakia) and Lipica $(7 \mathrm{~km}$ east of Trieste, Slovenia). All three generations of $C$. ohridella were sampled at all sites in 2001, whereas only the first generation, in spring, was sampled in the following years. Each population or generation was sampled once, i.e. when the first adults started to emerge, which was assessed for each site individually.

A minimum of 50 leaves, chosen at random, were examined under a stereomicroscope within $24 \mathrm{~h}$ of sampling. Between 500 and 700 mines per sample were opened. The number of living, dead, missing and parasitized larvae or pupae was recorded. The developmental stages of the larvae were determined by their head-capsule width, as described by Freise \& Heitland (2004) and grouped as follows: feeding larvae L1-L2 (L1-L3 in 2001); L3; L4; spinning larvae 1 and 2 (S1-S2); pupae (P); emerged adults. Parasitized, dead, weak or unhealthy larvae and all pupae were put singly into plastic Petri dishes. The Petri dishes were stored under laboratory conditions in plastic boxes, the bottoms of which were lined with moistened cotton wool. These dishes were checked daily and emerging parasitoids were kept for further identification. Details of the life cycles, feeding strategies and competitive interactions were recorded.

\section{Rates of parasitism and other mortality factors}

In 2001, stage-specific parasitism rates and other mortality rates were calculated for L1-L3, L4, the two spinning stages together and pupae. In 2002 and 2003, rates were calculated for L1-L2 and for L3 separately. The parasitism rate at stage $\mathrm{x}$ was calculated by dividing the number of parasitised hosts at stage $x$ by the number of insects dead or alive at stage $\mathrm{x}$ and the following stages, including emerged adults. Similarly, the rate of other mortality (= caused by other factors than parasitism) was calculated by dividing the number of dead hosts at stage $\mathrm{x}$ by the number of living or dead insects at stage $\mathrm{x}$ and the following stages, including emerged adults. They can be calculated using the following formulae:

$$
\begin{aligned}
& P N_{x}=\frac{N_{x}}{\sum_{x}^{5}\left(N_{x}+D_{x}+A_{x}\right)}(.100 \%) \\
& P D_{x}=\frac{D_{x}}{\sum_{x}^{5}\left(N_{x}+D_{x}+A_{x}\right)}(.100 \%)
\end{aligned}
$$

$P N_{x}$ - parasitism rate of developmental stage $\mathrm{x}$ $N_{x}$ - number of parasitized individuals of developmental stage $\mathrm{x}$ $P D_{x}$ - other mortality rate of developmental stage $\mathrm{x}$
$D_{x}$ - number of dead or missing individuals of developmental stage $\mathrm{x}$ (parasitism excluded)

$A_{x}$ - number of living individuals of developmental stage x

$x$ - developmental stage (1: L1-L2 in 2002-03 only; 2: L3 in 2002-03 and L1-L3 in 2001; 3: L4; 4: spinning larvae; 5: pupae; emerged adults of the same generation were included in the number of living pupae)

Total parasitism rates and total other mortality rates were calculated using a life table approach, i.e. by integrating the stagespecific rates and taking into account the survival rate from one stage to another:

for $\mathrm{x}=0$ :

$R N_{x}=100 . P N_{x+1}$

$R D_{x}=100 . P D_{x+1}$

for $\mathrm{x}=1-4$ :

$R N_{x}=P N_{x+1} \cdot\left(100-R N_{x-1}-R D_{x-1}\right)$

$R D_{x}=P D_{x+1} \cdot\left(100-R N_{x-1}-R D_{x-1}\right)$

$\operatorname{Pt} N=\sum_{0}^{4} R N_{x}$

$P t D=\sum_{0}^{4} R D_{x}$

$P t N$ - total parasitism rate

$P N_{x}$ - parasitism rate of developmental stage $\mathrm{x}$

$R N_{x}$ - value used for the calculation of the total parasitism rate

$P t D$ - total other mortality rate

$P D_{x}$ - mortality rate of developmental stage $\mathrm{x}$

$R D_{x}$ - value used for the calculation of the total other mortality rate

\section{RESULTS}

\section{Parasitoid complex of Cameraria ohridella}

A total of twelve hymenopteran parasitoid species, nine Eulophidae, two Ichneumonidae and one Braconidae, were reared from mines of $C$. ohridella during this study (Table 1). Ten parasitoid species were obtained in the Czech Republic, with the most abundant parasitoid species being Minotetrastichus frontalis, accounting for nearly $40 \%$ of the parasitized mines, and Pnigalio agraules, which was found in $19 \%$ of the parasitized mines. Only seven specimens, consisting of five different parasitoid species, were obtained from the sample from Slovenia in 2003. Parasitoids were more abundant in the sample from Slovakia, where 57 specimens, consisting of three different species, were obtained. The main parasitoids in Slovakia were Pediobius saulius (75\%) and Minotetrastichus frontalis (21\%). P. saulius was also present in Slovenia but was never reared from the numerous samples collected in the Czech Republic.

All parasitoids reared during this study were idiobionts. Pediobius saulius, Chrysocharis spp., Closterocerus trifasciatus and Itoplectis alternans developed at least partially internally whereas the others were entirely ectoparasitoids. Most parasitoids were reared from more than one developmental stage (Table 1). For example, $M$. frontalis was reared from all instars from L2 upwards. However, P. saulius and I. alternans were obtained exclusively from pupae. In general, only one parasitoid 
TABle 1. Parasitoid species reared from mines collected in the Czech Republic, Slovakia and Slovenia. Numbers indicate the number of adult parasitoids. Gregarious M. frontalis emerging from the same mine were counted as one emergence (the total number of individuals are in brackets).

\begin{tabular}{|c|c|c|c|c|c|c|c|c|}
\hline Location & & Bolevec & Košutka & Lochotín & Mikulka & Otín & Ilava & Lipica \\
\hline Country & & Czech R. & Czech R. & Czech R. & Czech R. & Czech R. & Slovakia & Slovenia \\
\hline Number of dissected mines & & 2900 & 2200 & 2200 & 2200 & 1400 & 700 & 500 \\
\hline \multirow[t]{2}{*}{ Years of collection } & & $2001-03$ & $2001-02$ & $2001-02$ & $2001-02$ & $2002-03$ & 2003 & 2003 \\
\hline & host stage attacked ${ }^{1}$ & & & & & & & \\
\hline \multicolumn{9}{|l|}{ EuLophidAe } \\
\hline Cirrospilus diallus (Walker) & $\mathrm{S} 1-\mathrm{S} 2$ & & & & & & & 1 \\
\hline Cirrospilus vittatus (Walker) & L1-L3 & & & & 4 & & & \\
\hline Closterocerus trifasciatus (Westwood) & L1-L3, S1-S2, P & 1 & & 1 & 2 & 1 & 2 & 1 \\
\hline Chrysocharis nephereus (Walker) & L1-L3, L4, P & 3 & 2 & 1 & & & & \\
\hline Chrysocharis nitetis (Walker) & $\mathrm{L} 4, \mathrm{P}$ & & & 1 & & 2 & & \\
\hline Chrysocharis sp. & L1-3 & & & & 1 & 1 & & \\
\hline Minotetrastichus frontalis (Nees) & L1-L2, L3, L4, S1-S2, P & $8(9)$ & $12(24)$ & $13(20)$ & $5(7)$ & $3(4)$ & $11(16)$ & $3(3)$ \\
\hline Pediobius saulius (Walker) & $\mathrm{P}$ & & & & & & 39 & 1 \\
\hline Pnigalio agraules (Walker) & L1-L3, L4, S1-S2 & 11 & 1 & 1 & 6 & 1 & & 1 \\
\hline Pnigalio pectinicornis (Linnaeus) & $\mathrm{L} 4, \mathrm{~S} 1-\mathrm{S} 2$ & 1 & & & 2 & & & \\
\hline $\begin{array}{l}\text { Pnigalio sp. } \\
\text { BRACONIDAE }\end{array}$ & L1-L3, L4, S1-S2 & 5 & & 1 & 2 & 2 & & \\
\hline $\begin{array}{l}\text { Colastes braconius (Haliday) } \\
\text { ICHNEUMONIDAE }\end{array}$ & $\mathrm{L} 4, \mathrm{~S} 1-\mathrm{S} 2$ & & 1 & & 1 & & & \\
\hline Itoplectis alternans (Gravenhorst) & $\mathrm{P}$ & & 2 & & & & & \\
\hline Scambus annulatus (Kiss) & $\mathrm{S} 1-\mathrm{S} 2, \mathrm{P}$ & 1 & 2 & 3 & 2 & & & \\
\hline Total number of individuals & & $30(31)$ & $20(32)$ & $21(28)$ & $25(27)$ & $10(11)$ & $52(57)$ & $7(7)$ \\
\hline
\end{tabular}

${ }^{1} \mathrm{~L}$ - feeding larvae; S - spinning larvae; P - pupae. In 2001, L1, L2 and L3 were grouped; in 2002 and 2003, L1 and L2 were grouped

developed per host, with the exception of M. frontalis, for which up to nine parasitoid larvae were found per mine and up to five per mine developed successfully. Hyperparasitism was observed in several cases. M. frontalis was found developing on ichneumonid larvae, probably Scambus annulatus, C. trifasciatus on eulophid larvae and pupae, and P. agraules on eulophid pupae. Multiparasitism was observed with $M$. frontalis/P. saulius and M. frontalis/C. trifasciatus.

\section{Parasitism and other mortality factors}

Parasitism rates and other mortality rates for all stages, generations and locations are shown in Table 2. In general, parasitism rates were very low in all feeding larvae, with stage-specific parasitism rates rarely above $1 \%$. Spinning stages and pupae were attacked more often, with stage-specific parasitism rates of up to $7.52 \%$ and $17.30 \%$, respectively. Total parasitism varied from $0.98 \%$ to $11.34 \%$ at the Czech sites and reached $14.59 \%$ at the Slovakian site. In 2001, when parasitism was measured for each of the three generations, total parasitism appeared similar in the first two generations (3.22-9.04 and 3.07-11.34, respectively) but dropped at all four sites in the $3^{\text {rd }}$ generation (1.03-5.96).

Other mortality rates were generally higher than parasitism rates (Table 2), and stage-specific mortality was higher in the young developmental stages and in pupae than in fourth instar larvae and spinning stages. Total other mortality rates varied from $6.99 \%$ to $62.30 \%$, with the highest rates found in the first generation in 2001 .

\section{DISCUSSION}

\section{Parasitoid complex of Cameraria ohridella}

The parasitoid complex found in the Czech Republic and at the two sites in Slovakia and Slovenia is similar to that recorded in studies in other regions of Europe (e.g. Pschorn-Walcher, 1997; Stolz, 1997; Čapek, 1999; Grabenweger \& Lethmayer, 1999; Balázs \& Thuróczy, 2000; Moreth et al., 2000; Balázs \& Pál, 2001; Hellrigl, 2001; Freise et al., 2002; Marchesini et al., 2002; Grabenweger, 2003; Freise \& Heitland, 2004; Stojanovic \& Markovic, 2004; Lupi, 2005; Grabenweger et al., 2005; Girardoz et al., 2006). In most of these studies, the eulophid Minotetrastichus frontalis, is cited as the main parasitoid of $C$. ohridella, as it was in our study in the Czech Republic. The pupal parasitoid Pediobius saulius dominates in south-eastern Europe (Freise et al., 2002; Grabenweger et al., 2005). In the rest of Europe, it is common on other leaf miners but rare or absent on $C$. ohridella. In our study, it was absent from the Czech sites but was the main parasitoid in Slovakia and was also present in Slovenia. It is not clear yet whether the Pediobius saulius attacking $C$. ohridella in south-eastern Europe represents a particular strain, or possibly another species. In any case, it would 
TABLE 2. Stage-specific and total rates of parasitism and other mortality factors for all samples collected in the Czech Republic, Slovakia and Slovenia in 2001-2003. Abbreviations for developmental stages as in Table 1.

\begin{tabular}{|c|c|c|c|c|c|c|c|c|c|c|c|c|c|c|c|c|c|c|c|c|c|}
\hline \multirow{2}{*}{$\begin{array}{l}\text { Locality } \\
\text { Year }\end{array}$} & \multicolumn{5}{|c|}{ Bolevec } & \multicolumn{4}{|c|}{ Košutka } & \multicolumn{4}{|c|}{ Lochotín } & \multicolumn{4}{|c|}{ Mikulka } & \multicolumn{2}{|c|}{ Otín } & \multicolumn{2}{|c|}{ Ilava Lipica } \\
\hline & & 2001 & & 2002 & 2003 & & 2001 & & 2002 & & 2001 & & 2002 & & 2001 & & 2002 & 2002 & 2003 & 2003 & 2003 \\
\hline Generation & 1 & 2 & 3 & 1 & 1 & 1 & 2 & 3 & 1 & 1 & 2 & 3 & 1 & 1 & 2 & 3 & 1 & 1 & 1 & 1 & 1 \\
\hline \multicolumn{22}{|c|}{ Parasitism rates } \\
\hline L1-L3 & 0.60 & 0.60 & 0 & & & 0.40 & 0 & 0 & & 1.40 & 0.20 & 0 & & 2.20 & 0 & 0 & & & & & \\
\hline L1-L2 & & & & 0 & 0 & & & & 0 & & & & 0.14 & & & & 1 & 0.71 & 1 & 0.14 & 0 \\
\hline L3 & & & & 0 & 0.34 & & & & 0.28 & & & & 0 & & & & 0.34 & 0.8 & 0.86 & 0.68 & 0.49 \\
\hline L4 & 1.38 & 0.75 & 0 & 0.16 & 1.63 & 0.40 & 0.34 & 0.49 & 0.99 & 0 & 0.41 & 0 & 0.83 & 0.45 & 0.44 & 0.98 & 0.55 & 0.92 & 0.80 & 0 & 0.27 \\
\hline $\mathrm{S} 1-\mathrm{S} 2$ & 1.08 & 0 & 1.34 & 0.36 & 7.57 & 0 & 4.84 & 0 & 1.72 & 0 & 0 & 3.43 & 1.47 & 2.17 & 2.92 & 0.69 & 3.22 & 0.32 & 2.91 & 0.80 & 2.35 \\
\hline $\mathrm{P}$ & 9.09 & 12.50 & 0 & 0.58 & 0.60 & 6.38 & 4.35 & 1.57 & 2.85 & 6.45 & 7.89 & 3.87 & 4.29 & 0 & 0 & 1.1 & 1.87 & 1.19 & 4.86 & 17.3 & 7.02 \\
\hline Total & 9.04 & 11.34 & 1.03 & 0.98 & 8.38 & 3.22 & 8.95 & 1.67 & 5.13 & 6.24 & 8.15 & 5.96 & 5.46 & 3.39 & 3.07 & 2.44 & 5.79 & 3.51 & 8.47 & 14.59 & 7.99 \\
\hline \multicolumn{22}{|c|}{ Other mortality rates } \\
\hline L1-L3 & 23.20 & 17.20 & 10.40 & & & 12.00 & 2.00 & 14.20 & & 17.00 & 3.60 & 14.00 & & 13.20 & 7.00 & 6.60 & & & & & \\
\hline L1-L2 & & & & 7.43 & 13.57 & & & & 5.57 & & & & 11.86 & & & & 13.71 & 7.43 & 7.57 & 16.86 & 14.20 \\
\hline L3 & & & & 0.31 & 1.69 & & & & 4.23 & & & & 5.15 & & & & 2.35 & 3.36 & 10.96 & 4.51 & 3.45 \\
\hline L4 & 2.30 & 1.49 & 13.86 & 2.05 & 0.91 & 53.78 & 1.72 & 4.63 & 0.66 & 4.72 & 0 & 1.76 & 1.66 & 55.36 & 1.76 & 5.85 & 2.00 & 1.66 & 0.60 & 1.76 & 1.91 \\
\hline $\mathrm{S} 1-\mathrm{S} 2$ & 0 & 0 & 6.71 & 1.45 & 0.52 & 3.67 & 0 & 2.16 & 1.38 & 3.51 & 0 & 2.94 & 0.29 & 2.17 & 5.11 & 2.78 & 1.75 & 2.90 & 0.65 & 0 & 1.18 \\
\hline $\mathrm{P}$ & 20.00 & 12.50 & 22.03 & 0.18 & 8.13 & 0 & 5.80 & 1.18 & 1.78 & 0 & 5.26 & 7.74 & 3.07 & 4.08 & 4.62 & 16.48 & 46.27 & 5.56 & 0.65 & 7.03 & 16.23 \\
\hline Total & 39.47 & 28.55 & 43.63 & 11.08 & 22.4 & 60.58 & 6.99 & 20.87 & 12.57 & 23.58 & 8.64 & 24.11 & 20.47 & 62.3 & 10.15 & 28.32 & 54.35 & 19.09 & 19.09 & 27.38 & 32.31 \\
\hline
\end{tabular}

be interesting to follow the spread of $P$. saulius on $C$. ohridella towards the west and the north.

The single specimen of Cirrospilus diallus obtained at the Slovenian site represents a new parasitoid record for C. ohridella. C. diallus is a polyphagous idiobiont ectoparasitoid of various leaf miners, occurring in the Palaearctic region (Noyes, 2002).

\section{Parasitism and other mortality factors}

The present study confirmed the minor role of parasitism in the mortality of $C$. ohridella. Only $1 \%$ to $17 \%$ of the moths died from parasitism in the larval and pupal stages. These numbers are in accordance with other studies on parasitism, despite the fact that different methods of calculation were used. For example, Freise et al. (2002), who calculated total parasitism by dividing the number of parasitized hosts by the total number of mines containing living hosts or parasitoids, mention parasitism rates from $1.7 \%$ to $13.7 \%$ in Serbia and Macedonia. Using a similar method of calculation, Grabenweger et al. (2005) found parasitism rates of 3.6-21.0\% in the Balkans. They also showed that parasitism is not higher in natural horse-chestnut stands than on planted trees in urban areas. Parasitism tends to be even lower in other European regions, because of the scarcity or absence of Pediobius saulius (e.g. Pschorn-Walcher, 1997; Grabenweger \& Lethmayer, 1999; Hellrigl, 2001; Marchesini et al., 2002; Grabenweger, 2003; Freise \& Heitland, 2004; Lupi, 2005). In Germany, Freise \& Heitland (2004) dissected tens of thousands of mines and stated that total parasitism never exceeded 5\% per generation. Grabenweger (2003) mentioned a parasitism rate of $9.8 \%$ in Austria, which was calculated by dividing the number of emerged adult parasitoids by the total number of mines, although he stated that this number was probably overestimated because the main parasitoid found, Minotetrastichus frontalis, is gregarious. Grabenweger (2003) also provided data on parasitism at various periods during the spring generation and stated that spinning larvae are the most frequently parasitized stage. However, before the present study, the only other publication giving precise stage-specific parasitism rates is Girardoz et al. (2006) who, using the same method of calculation, observed similar patterns of parasitism in Switzerland, with parasitism rates of spinning larvae and pupae higher than of feeding larvae. Considering the short duration of the two spinning stages, which in total do not last more than a few days (M. Kenis, pers. observ.), it is surprising to observe that they are more parasitized than the $4^{\text {th }}$ instar, which is the longest larval stage. As mentioned by Grabenweger (2003), larvae in the feeding stage are more mobile and able to defend themselves than when in the spinning stage. Pupae are theoretically more exposed to parasitoids because they are less mobile than the $4^{\text {th }}$ instar and last longer than the spinning larvae; however, in Central Europe, they tend to be less parasitized than the spinning stage (Grabenweger, 2003; Girardoz et al., 2006; this study, Czech results), perhaps because some of the parasitoids, such as Pnigalio agraules, tend to avoid, or are not able to parasitize pupae. In contrast, pupal parasitism is highest in regions where $P$. saulius is the main parasitoid, as in the sample from Slovakia (see also Freise et al., 2002; Grabenweger et al., 2005).

While we are confident that our method for calculating stage-specific parasitism rates provides a good estimate of parasitized larvae and pupae, it is more difficult to provide reliable total parasitism rates. We believe that the method proposed here gives a better idea of the proportion of the immature stages that are actually killed by parasitism than previous methods. This method, based on the integration of stage-specific parasitism rates and mortality that is not directly attributed to parasitism, avoids two main biases frequently encountered in other studies. Firstly, the dissection of mines avoids the errors caused by (1) multiparasitism/superparasitism and (2) different mortality rates in rearing between parasitoids and non- 
parasitized hosts. Secondly, compared to other methods based on mine dissections, our method is independent of the sampling date and the proportion of the different developmental stages in the samples. As observed in this study, the parasitism rate greatly varies among developmental stages. When parasitism rates are based simply on the number of parasitized mines (e.g. divided by the total number of mines or by the number of living hosts or parasitoids), a sample containing mostly $4^{\text {th }}$ instar larvae provides fewer parasitoids and, consequently, a much lower parasitism rate than a sample taken later, when most hosts are in the pupal stage. However, to get a proper idea of the exact proportion of the population that is actually killed by parasitoids, at least two other parameters need to be taken into account. Firstly, host feeding should be added to apparent parasitism. Host feeding is common in leaf miner parasitoids and can be a major cause of mortality (Askew \& Shaw, 1979). Although preliminary observations tend to show that host feeding is of minor importance in the mortality of $C$. ohridella (S. Girardoz and M. Kenis, unpubl. data) it is very likely that at least a small part of the "other mortality" observed in this study is caused by host feeding. Secondly, the other mortality factors and their interactions with parasitism should be studied in detail to properly assess the mortality that can really be attributed to parasitoids. In this study, we observed mortality in general, without detailing the different components of this mortality (e.g. invertebrate predators, birds, host-tree resistance, host feeding by parasitoids, etc.). All of these may affect parasitism in a different way. Furthermore, important mortality factors were excluded from the analysis, such as winter mortality, and mortality caused by intraspecific competition and leaf senescence in autumn. Had these mortality factors been included, mortality in the last (autumn-spring) generation would have been much higher than in the two other generations. Investigating the whole complex of mortality factors in a life table study would give a better understanding of the lack of natural control of populations of C. ohridella in Europe and evaluation of the potential for biological control, through the enhancement of native natural enemies or introduction of exotic parasitoids (Kenis et al., 2005).

ACKNOWLEDGEMENT. We are grateful to H. Baur (Natural History Museum, Bern) and G. Grabenweger (University of Natural Resources and Applied Life Sciences, Vienna, and Official Bureau of Plant Protection Berlin) for their help in the determination of the parasitoid species and to J. Miall for his comments on the manuscript.

\section{REFERENCES}

AsKew R.R. \& SHAW M.R. 1979: Mortality factors affecting the leaf-mining stages of Phyllonorycter (Lepidoptera: Gracillariidae) on oak and birch: 1. Analysis of the mortality factors. Zool. J. Linn. Soc. 67: 31-49.

Balázs K. \& PÁl B. 2001: Parasitoiden der RoßkastanienMiniermotte (Cameraria ohridella Deschka \& Dimić, 1986) in Nordwest-Ungarn. Acta Agron. Ovariensis 43: 35-48.
Balázs K. \& Thuróczy Cs. 2000: Über den Parasitoidkomplex von Cameraria ohridella Deschka et Dimić 1986, (Lepidoptera, Lithocolletidae). Entomol. Basil. 22: 269-277.

CAPEK M. 1999: Parasitoids of the horse-chestnut leafminer. In Laštůvka Z. (ed): Horse-Chestnut Leafminer (Cameraria ohridella Deschka \& Dimić, 1986). Veronica 13 (appendix). Brno, pp. 1-12 [in Czech].

Freise J.F. \& Heitland W. 2004: Bionomics of the horsechestnut leaf miner Cameraria ohridella Deschka \& Dimic 1986, a pest on Aesculus hippocastanum in Europe (Insecta, Lepidoptera, Gracillariidae). Senckenb. Biol. 84: 61-80.

Freise J.F., Heitland W. \& Tosevski I. 2002: Parasitism of the horse-chestnut leaf miner, Cameraria ohridella Deschka \& Dimić (Lep., Gracillariidae), in Serbia and Macedonia. J. Pest Sc. 75: 152-157.

Gibogini B., Alma A. \& Arzone A. 1996: Ricerche bioetologiche su Imenotteri della biocenosi di Phyllonorycter robiniellus (Clemens) (Lepidoptera: Gracillariidae). Boll. Zool. Agr. Bachicol. (Ser. 11) 28: 13-22.

Girardoz S., Kenis M. \& Quicke D.L.J. 2006: Recruitment of native parasitoids by an exotic leaf miner, Cameraria ohridella: host-parasitoid synchronisation and influence of the environment. Agric. For. Entomol. (in press).

Godfray H.C.J., Agassiz D.L.J., Nash D.R. \& Lawton J.H. 1995: The recruitment of parasitoid species to two invading herbivores. J. Anim. Ecol. 64: 393-402.

Grabenweger G. 2003: Parasitism of different larval stages of Cameraria ohridella. BioControl 48: 671-684.

Grabenweger G. \& Lethmayer C. 1999: Occurrence and phenology of parasitic Chalcidoidea on the horse chestnut leafminer, Cameraria ohridella Deschka \& Dimić (Lep., Gracillariidae). J. Appl. Entomol. 123: 257-260.

Grabenweger G., Avtzis N., Girardoz S., Hrasovec B., Tomov R. \& KenIs M. 2005: Parasitism of Cameraria ohridella (Lepidoptera, Gracillariidae) in natural and artificial horse-chestnut stands in the Balkans. Agric. For. Entomol. 7: 291-296.

Hellrigl K. 2001: Neue Erkenntnisse und Untersuchungen über die Roßkastanien-Miniermotte. Gredleriana 1: 9-91.

Kenis M., Tomov R., Svatos A., Schlinsog P., Lopez Vaamonde C., Heitland W., Grabenweger G., Girardoz S., Freise J. \& Avtzis N. 2005: The horse-chestnut leaf miner in Europe. Prospects and constraints for biological control. In Hoddle M. (ed.): Proceedings of the Second International Symposium on Biological Control of Arthropods, Davos, Switzerland, 12-16 September. Forest Health Technology Enterprise Team, Morgantown, WV, pp. 77-90.

Laštưvka Z., LišKa J., VÁvra J., Elsner V., Laštưvka A., Marek J., Dufek T., Dvořák M., Kopeček F., Petrư M., Skyva J. \& Vítek P. 1994: Faunistic records from the Czech Republic. Klapalekiana 18: 197-206.

LuPI D. 2005: A 3 year survey of the natural enemies of the horse-chestnut leaf miner Cameraria ohridella in Lombardy, Italy. BioControl 50: 113-126.

Marchesini E., Pasini M. \& Galbero G. 2002: Parassitoidi della minatrice fogliare degli ippocastani. Inform. Agr. 27: 75-77.

Moreth L., Baur H., Schönitzer K. \& Diller E. 2000: Zum Parasitoid-Komplex der Roßkastanien-Miniermotte in Bayern (Cameraria ohridella, Gracillariidae, Lithocolletinae). Mitt. Dt. Ges. Allgem. Angew. Entomol. 12: 489-492.

Noyes J.S. 2002: Interactive Catalogue of World Chalcidoidea 2001. CD Rom. Taxapad, Vancouver.

Pschorn-Walcher H. 1997: Zur Biologie und Populationsentwicklung der eingeschleppten Roßkastanien-Miniermotte, Cameraria ohridella. Forstsch. Aktuell 21: 7-10. 
Stojanović A. \& Marković C. 2004: Parasitoid complex of Cameraria ohridella (Lepidoptera: Gracillariidae) in Serbia. Phytoparasitica 32: 132-140.

Stolz M. 1997: Untersuchungen über Larval- und Puppenparasitoide von Cameraria ohridella in Hinblick auf ihre Eignung zur Laborzucht. Forstsch. Aktuell 21: 31.

ŠEFrová H. 1998: Occurrence of Phyllonorycter leucographellus in the Czech Republic. Plant Prot. Sci. 34: 112-113 [in Czech, English abstr.].

Š́frová H. 2002a: Phyllonorycter robiniella (Clemens, 1859) egg, larva, bionomics and its spread in Europe (Lepidoptera, Gracillariidae). Acta Univ. Agric. Silvic. Mendel. Brun. 51: $7-12$.

Šefrová H. 2002b: Phyllonorycter medicaginella (Gerasimov, 1930) - Larval morphology, bionomics and spread in Europe
(Lepidoptera, Gracillariidae). Acta Univ. Agric. Silvic. Mendel. Brun. 58: 85-90.

ŠEfrová H. 2002c: Phyllonorycter issikii (Kumata, 1963) bionomics, ecological impact and spread in Europe (Lepidoptera, Gracillariidae). Acta Univ. Agric. Silvic. Mendel. Brun. 60: $99-104$.

Urbaneja A., Llácer E., Tomás O., Garrido A. \& Jacas J.-A. 2000: Indigenous natural enemies associated with Phyllocnistis citrella (Lepidotera: Gracillariidae) in eastern Spain. Biol. Control 18: 199-207.

VAN DRIESChe R.G. 1983: The meaning of "percent parasitism" in studies of insect parasitoids. Environ. Entomol. 12: 1611-1622.

Received June 15, 2005; revised and accepted November 18, 2005 